\title{
Numerical Study of a Building Using Phase Change Materials (PCMs) in Reunion Island
}

\author{
S. Guichard, F. Miranville, B. Malet-Damour, D. Bigot, H. Boyer, and T. Libelle
}

\begin{abstract}
Buildings in Reunion Island have different thermal performances so the thermal energy storage should be enhanced. Using phase change materials in the building envelope could be a solution. These materials are able to increase the low thermal mass of lightweight constructions in order to improve human comfort, maintaining the building ambient thermal comfort closer to the desired temperature. The main objective of this paper is to present the thermal impact of PCM on two walls of an office with Reunion Island specific conditions. To this end, the experimental validation of a model based on the apparent heat capacity method and integrated into a building simulation code is used. The study results are very encouraging.
\end{abstract}

Index Terms-Building simulation code, phase change materials, thermal energy storage.

\section{INTRODUCTION}

Reunion Island is a French overseas department located in the Indian Ocean near Madagascar, characterized by a tropical and humid climate. Since before May 1st 2010, no regulations have been found in the building sector. That is why, the first chosen building construction mode led to buildings with different energetic performances. To avoid those problems again thermal, acoustic and ventilation standards regulations were approved and are applicable to new dwellings or extensions to existing residential buildings. Current regulations are a major step in building design in order to help curb energy consumption and to protect the environment using renewable energies and reducing greenhouse gases emissions [1]. Another possibility to contribute to the passive building design is to use phase change materials. PCMs can be defined as any organic (or inorganic) compound, able to store and release energy in latent heat form during phase change from liquid state to solid state (or vice versa) at uniform temperature [2]. However, they are not considered as a supplementary thermal insulation material according to the current regulations (RTAA DOM in French). Nevertheless, the literature results [3] have shown that the PCM can enhance the thermal energy storage capacity of the building envelope, and the effect of

Manuscript received August 1, 2015; revised October 21, 2015.

$\mathrm{S}$. Guichard is with the Research Institute in Innovation and Business Sciences (IRISE) Laboratory in partnership with CCIR, the CESI Engineering School, France (e-mail: sguichard@cesi.fr).

F. Miranville, B. Malet-Damour, D. Bigot, H. Boyer, and T. Libelle are with the Physics and Mathematical Engineering Laboratory for Energy and Environment (PIMENT), University of La Reunion, France (e-mail: frederic.miranville@univ-reunion.fr, bruno.malet-damour@univ-reunion.fr, dimitri.bigot@univ-reunion.fr, teddy.libelle@univ-reunion.fr). fluctuations from the external environment on the internal air temperature of the building may be minimized. Furthermore, the temperature rise may be delayed thanks to the increase of thermal mass of walls. To evaluate the thermal effect of PCM on the internal air temperature of the building, the paper deals with a numerical study of a monozone building according to current regulations and integrating PCM panels into walls. Despite phase change materials are not always defined as a supplementary thermal insulation according to French regulation, the study would show if PCM panels could be used to improve the building thermal-storage systems. To perform the numerical study, the use of building thermal simulation code is required. So, we use a thermal building simulation code named ISOLAB, developed with MATLAB platform, to simulate the temperature field of the building by taking into account its description and the real weather conditions [4]. A thermal model for phase change materials was integrated in ISOLAB [2], [5]. We are first going to present the study case and the building simulation code. Then, the simulation results are shown and finally the conclusions of this study are revealed.

\section{PROBLEM STATEMENT}

The considered physical system is a cubic-shaped building composed by a single blind window on the South wall and a glass door on the North wall. It is representative of a small dwelling, similar to a bedroom or an office with the following dimensions: 3 m (height) x 3 m (weight) x 3 m (length), (see Fig. 1). Current regulations are applied to the building envelopes. From interior to exterior, all vertical walls are made of concrete blocks ( $0.1 \mathrm{~m}$ thickness), polystyrene (0.01 $\mathrm{m}$ thickness) and plasterboard (0.013 m thickness). The floor is constituted of weight concrete ( $0.2 \mathrm{~m}$ thickness), polystyrene (0.045 $\mathrm{m}$ thickness) and concrete slabs (0.045 m thickness). The roof is composed by corrugated iron (0.001 m thickness), glass wool (0.045 m thickness), PCM panels (5 mm thickness) and drywall (0.013 m thickness). The test cell is considered well-isolated according to current regulations. The building is oriented according to the geographic North (see Fig. 1).
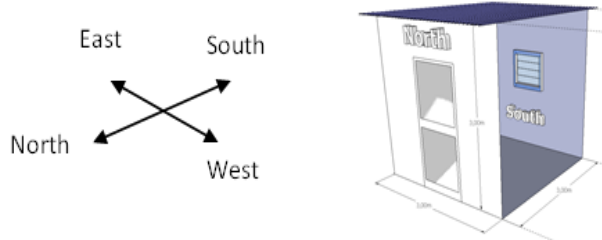

Fig. 1. The studied test cell. 


\section{DESCRIPTION OF PCM MODEL INTEGRATED IN ISOLAB}

Isolab is a building simulation code. It is able to predict energetic behavior of a monozone or multi-zone building, according to its description and the location climate of its location. Each zone of the building is based on nodal analysis [4]. The conduction heat transfer through walls is one-dimensional. To predict the thermal behavior of the building, in order to determine temperatures or heat fluxes for example, the following matricial formalism (1) is solved by using an implicit finite-difference method.

$$
\dot{T}_{W}=A_{w} T_{W}+B_{W}
$$

where, the index $W$ used for walls; $T$ the vector containing all temperatures nodes of each wall; $\dot{T}$ the temperature derivative of $T$; $A$ the state matrix including terms for conductive, convective and radiative models; $B$ the solicitations vector.

Isolab was validated with the IEA BESTEST procedure (International Energy Agency for Building Energy Simulation Test) for buildings without PCMs [4]. Since May 2013, a thermal model for phase change (2) based on heat apparent capacity method has been elaborated respecting the state system formalism of Isolab code, in order to integrate this latter [5]. The model developed, called MCPbat, is able to predict, both the temperatures of PCM and the temperature of homogenous materials, integrated into the building envelope.

$$
C_{a p p}(T) \frac{\partial T(x, t)}{\partial t}=\lambda_{P C M}(T) \frac{\partial^{2} T(x, t)}{\partial x^{2}}
$$

where, $C_{a p p}$ the heat apparent capacity and $\lambda_{\text {PCM }}$ the thermal conductivity. These parameters depend on temperature.

In our approach, the solid fraction expression allows to use a backward Euler scheme, without tracking the phase change interface. Its expression is given by (3).

$$
f_{s}(T)=\frac{1}{2}-\frac{1}{2} \tanh \left(\gamma \frac{T_{m}-T(x, t)}{4 \delta T}\right)
$$

where, $\gamma$ is a specific parameter determined by optimization [5] ; $\delta T$ the temperature range over which the phase change occurs ; $T_{m}$ the temperature of phase change.

The numerical simulation results of MCPbat have already been compared with other simulation code results and an experimental case. Indeed, an experimental study was conducted in a full-scale outdoor test cell equipped with PCM panels on a roofing complex in order to validate the thermal model for phase change materials and to check the correct implementation of this latter in ISOLAB code. Therefore, different steps of the validation process were run [2], [6]. So, the PCM numerical thermal model was validated according to the PIMENT laboratory's methodology and only if the validation criteria were reached. Furthermore, the results have shown that the PCM thermal model was fully-coupled with ISOLAB code, and the inside air temperature of the test cell was predicted with an accuracy of $\pm 0.5^{\circ} \mathrm{C}$. The interested reader can refer to [5] for further information. Now, Isolab code allows the thermal behavior simulation of the building equipped with PCM or without PCM. Thus, we can simulate two identical buildings; excepted one is equipped with PCM panels in the North and the South walls, and the other one without PCM, in order to determine the thermal effect of PCM on the internal air temperature.

\section{Numerical Simulations}

\section{A. Climatic Data}

The chosen period covered eleven days of June 2011, during which the weather conditions ensured the phase change and regeneration of PCM. Indeed, the climatic conditions correspond to the winter season in Reunion Island. The database from the meteorological station is measured every minute and every 5 minutes, an average value is calculated. For instance, the solar radiation is depicted in Fig. 2.

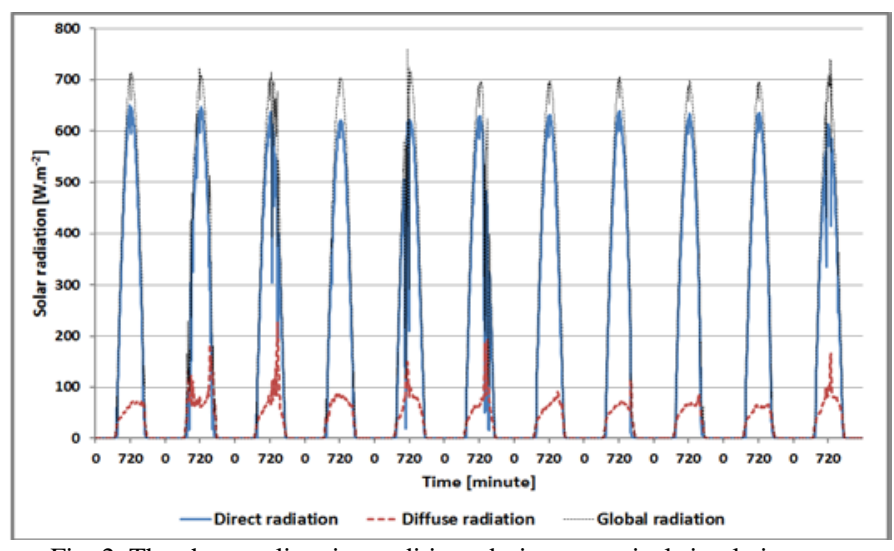

Fig. 2. The chosen climatic conditions during numerical simulations.

\section{B. Simulation Assumptions}

Following assumptions were made to perform the numerical study:

- Only thermo-physical properties of PCM depend on temperature.

- Due to forced convection effect, the convective heat transfer from the outer surface of corrugated iron is described using the local experimental correlation [4]: $h_{c e}=5.7 \mathrm{~V}+11.4$, with $\mathrm{V}$ the wind speed.

- Initializing indoor temperature of the building to $25^{\circ} \mathrm{C}$.

- The time step is equal to $300 \mathrm{~s}$.

- Indoor and outdoor convective exchange coefficients $\left(h_{c i}\right.$ and $h_{c e}$ ) are constant for each wall and are respectively: $h_{c i}=3.5 \mathrm{~W} \cdot \mathrm{m}^{-2} \cdot \mathrm{K}^{-1}$ and $h_{c i}=11.7 \mathrm{~W} \cdot \mathrm{m}^{-2} \cdot \mathrm{K}^{-1}$.

- Fictive sky temperature $\left(T_{\text {sky }}\right)$ is defined by the following correlation for tropical climate [7]: $T_{s k y}=T_{a i}-6$, with Tai the ambient temperature.

- The radiative exchange coefficients are constant for each wall: $h_{r i}=5 \mathrm{~W} \cdot \mathrm{m}^{-2} \cdot \mathrm{K}^{-1}$.

- For indoor and outdoor long-wave radiation heat transfer ( $\varphi_{\text {lwr,in }}$ and $\varphi_{\text {lwr,out }}$ ), the following models are 
respectively: $\varphi_{l w r, \text { in }}=h_{r i}\left(T_{r m}-T_{s i, w}\right)$ and $\varphi_{l w r, o u t}=H_{p c}$ $\left(T_{s k y}-T_{s e, w}\right)+H_{p e}\left(T_{e n v}-T_{s e, w}\right)$ With $T_{r m}$ the mean radiant temperature; $T_{s i}$ the inside surface temperature of the wall; $T_{s e, w}$ the outside surface temperature of the wall; $H_{p c}$ and $H_{p e}$ are given by [8].

- According to weather conditions, the PCM thermo-physical properties from Rubitherm ${ }^{\circledR} \mathrm{GmbH}$ website are used for simulations [9]. The thickness of the PCM panel is chosen arbitrarily and very small. Its characteristics are indicated in Table I.

TABLE I: CHARACTERISTICS OF PCM USED

\begin{tabular}{lll}
\hline \hline Parameter & Value & Unit \\
\hline Thermal conductivity $: \lambda_{\mathrm{s}} / \lambda_{\mathrm{l}}$ & $0.2 / 0.2$ & $\mathrm{~W} \cdot \mathrm{m}^{-1} \cdot \mathrm{K}^{-1}$ \\
Heat Capacity: $\mathrm{C}_{\mathrm{ps}} / \mathrm{C}_{\mathrm{pl}}$ & $2000 / 2000$ & $\mathrm{~J} \cdot \mathrm{kg}^{-1} \cdot \mathrm{K}^{-1}$ \\
Latent heat: $\mathrm{L}_{\mathrm{m}}$ & 230000 & $\mathrm{~J} . \mathrm{kg}^{-1}$ \\
Phase change temperature: $\mathrm{T}_{\mathrm{m}}$ & 25 & ${ }^{\circ} \mathrm{C}$ \\
Heat density: $\rho_{\mathrm{s}} / \rho_{\mathrm{l}}$ & $880 / 770$ & $\mathrm{~kg} \cdot \mathrm{m}^{-3}$ \\
Thickness & 5 & $\mathrm{~mm}$ \\
\hline \hline
\end{tabular}

\section{Results and Discussion}

TABLE II: RESIDUES OF THE TEMPERATURE DIFFERENCE BETWEEN THE TEST BUILDING WITH AND WITHOUT PCM

\begin{tabular}{cccc}
\hline \multicolumn{4}{c}{ TEST BUILDING WITH AND WITHOUT PCM } \\
\hline $\begin{array}{c}\text { Interior surface } \\
\text { temperature of the } \\
\text { North wall }\end{array}$ & $\begin{array}{c}\text { Interior surface } \\
\text { temperature of } \\
\text { the South wall }\end{array}$ & $\begin{array}{c}\text { Inside air } \\
\text { temperature }\end{array}$ \\
\hline Minimum & $2.3^{\circ} \mathrm{C}$ & $2.1^{\circ} \mathrm{C}$ & $1.4^{\circ} \mathrm{C}$ \\
Maximum & $3.5^{\circ} \mathrm{C}$ & $2.8^{\circ} \mathrm{C}$ & $2.0^{\circ} \mathrm{C}$ \\
\hline \hline
\end{tabular}

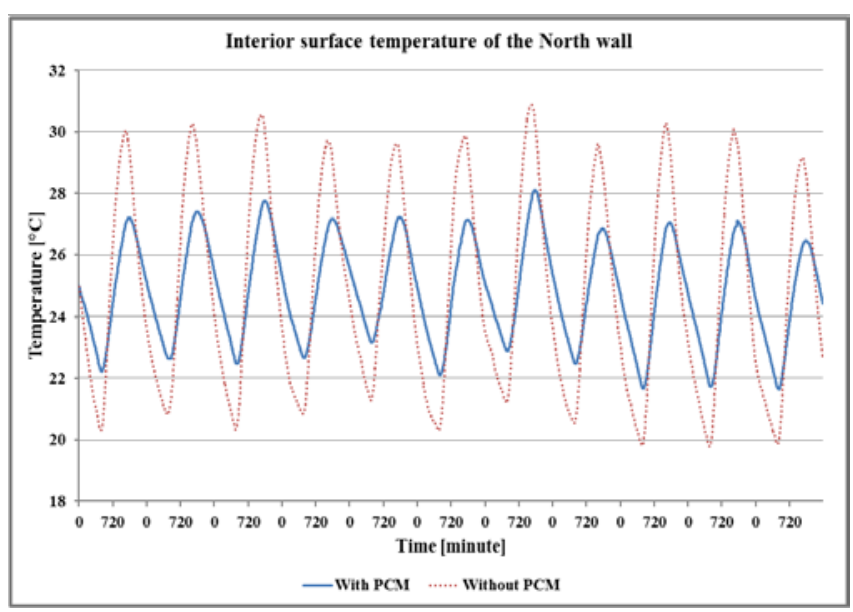

(a) Interior surface temperature of the North wall.

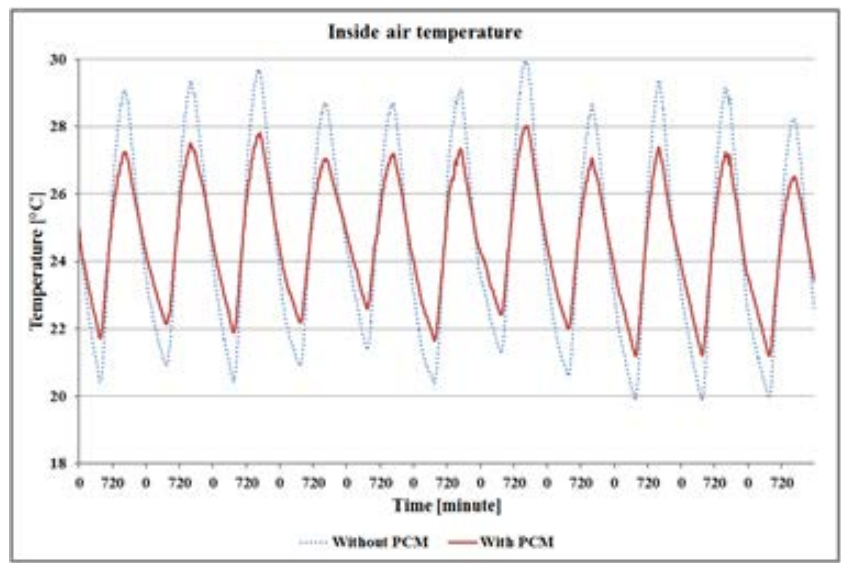

(b) Inside air temperature of the building.

Fig. 3. Time-temperature profiles for the North wall, and air within the building.

\section{CONCLUSIONS AND FURTHER WORK}

The current study presents the numerical simulations of PCM panels integrated into the building envelope. The results clearly put in evidence the PCM effect on the internal air temperature when integrated into two walls of the building. Indeed, the results show that the peak temperature within the building is up to $2^{\circ} \mathrm{C}$ less than the test building during day time and the heating load can be reduced at night. As a result, the thermal mass of lightweight building material can be improved using phase change materials as a thermal energy storage system. So, PCM can be used as a supplementary thermal insulation in order to improve the building energy efficiency by enhancing the storage and releasing energy. PCM seems a possible solution to contribute to current regulations, both to enhance the thermal comfort and to reach a high energetic performance of the building for tropical and humid climates. Nevertheless, experimental studies should be conducted to highlight the numerical simulation results obtained. The thermal comfort study according to Givoni's psychrometric chart will be presented in a future publication.

\section{ACKNOWLEDGMENT}

This research received funding the Ministère de l'Outre-Mer.

\section{REFERENCES}

[1] RTAA DOM. [Online]. Available: http://begreen-engineering.com/en/sustainable-development/certificati ons-and-standards/french/122-rtaa-dom

[2] S. Guichard, F. Miranville, D. Bigot, and H. Boyer, "A thermal model for phase change materials in a building roof for a tropical and humid climate: Model description and elements of validation," Energy and Buildings, vol. 70, pp. 71-80, 2014.

[3] A. M. Khudhair and M. M. Farid, "A review on energy conservation in building applications with thermal storage by latent heat using phase change materials,” Energy Conversion and Management, vol. 45, pp. 263-275, 2004

[4] F. Miranville, "Study of complex walls in building physics: Modelling and global validation of radiant barrier roof systems in tropical climatic conditions,” Ph.D. dissertation, University of La Réunion, 2002.

[5] S. Guichard, "Contribution to the study of inclusion of phase change materials into complex walls: Modelling, experiments and global energetic performance evaluation,” Ph.D. dissertation, University of La Réunion, 2013.

[6] D. Bigot, F. Miranville, H. Boyer, M. Bojic, S. Guichard, and A. Jean, "Model optimization and validation with experimental data using the case study of a building equipped with photovoltaic panel on roof: Coupling of the building thermal simulation code ISOLAB with the generic optimization program GenOpt,” Energy and Buildings, vol. 58, pp. 333-347, 2013.

[7] L. Adelard, F. Pignolet-Tardan, T. Mara, P. Lauret, F. Garde, and H. Boyer, "Sky temperature modelisation and applications in building simulation,” Renewable Energy, vol. 15, pp. 418-430, 1998.

[8] D. Caccavelli, "Modélisation du comportement thermique des bâtiments multizones,” Ph.D. dissertation, Institu National des Sciences Appliquées de Lyon, 1988.

[9] Rubiterm Phase Change Materials. [Online]. Available: http://www.rubitherm.de/english/index.htm

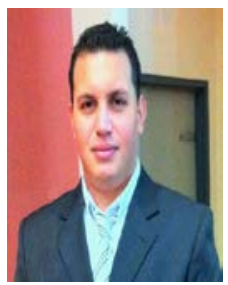

Stéphane Guichard was born in Reunion Island, a French overseas department located in the Indian Ocean. He was born on the $3^{\text {th }}$ of June in 1995. Stephane Guichard completed all his studies at the University of La Reunion. In 2010, he joined the team of Building Physics of the PIMENT laboratory, as a $\mathrm{PhD}$ student. His research work was based on phase change materials, both experimental and numerical 
approaches were conducted. A mathematical model dedicated to phase change materials was developed and validated with experimental data. $\mathrm{He}$ obtained his doctorate of civil engineering and energetics in May 2013.

From 2010 to 2014, he taught physics and mathematics in University of La Reunion. From October 2013 to August 2014, he was study director in environmental engineering in the University Institute of Technology of La
Reunion. Since September 2014, he is an assistant professor at the CES engineering school. He is a member of team of the Research Institute in Innovation and Business Sciences (IRISE) Laboratory and his main research topics are thermal insulation and phase change materials. 